\title{
Review
}

\section{Untold New Beginnings: Adult Hippocampal Neurogenesis and Alzheimer's Disease}

\author{
Catia M. Teixeira ${ }^{\mathrm{a}, 1}$, Noemí Pallas-Bazarra ${ }^{\mathrm{b}, \mathrm{c}, 1}$, Marta Bolós ${ }^{\mathrm{b}, \mathrm{c}, 1}$, Julia Terreros-Roncal ${ }^{\mathrm{b}, \mathrm{c}}$, \\ Jesús Ávila ${ }^{\mathrm{b}, \mathrm{c}}$ and María Llorens-Martín ${ }^{\mathrm{b}, \mathrm{c}, \mathrm{d}, *}$ \\ ${ }^{a}$ Emotional Brain Institute, Nathan Kline Institute, New York, NY, USA \\ ' Department of Molecular Neuropathology, Centro de Biología Molecular "Severo Ochoa", CBMSO, \\ CSIC-UAM, Madrid, Spain \\ ${ }^{\mathrm{c}}$ Center for Networked Biomedical Research on neurodegenerative diseases (CIBERNED), Madrid, Spain \\ ${ }^{\mathrm{d}}$ Department of Molecular Biology, Faculty of Sciences, Universidad Autónoma de Madrid, Madrid, Spain
}

\begin{abstract}
Neurogenesis occurs in a limited number of brain regions during adulthood. Of these, the hippocampus has attracted great interest due to its involvement in memory processing. Moreover, both the hippocampus and the main area that innervates this structure, namely the entorhinal cortex, show remarkable atrophy in patients with Alzheimer's disease (AD). Adult hippocampal neurogenesis is a process that continuously gives rise to newborn granule neurons in the dentate gyrus. These cells coexist with developmentally generated granule neurons in this structure, and both cooperative and competition phenomena regulate the communication between these two types of cells. Importantly, it has been revealed that GSK-3 $\beta$ and tau proteins, which are two of the main players driving AD pathology, are cornerstones of adult hippocampal neurogenesis regulation. We have shown that alterations either promoting or impeding the actions of these two proteins have detrimental effects on the structural plasticity of granule neurons. Of note, these impairments occur both under basal conditions and in response to detrimental and neuroprotective stimuli. Thus, in order to achieve the full effectiveness of future therapies for AD, we propose that attention be turned toward identifying the pathological and physiological actions of the proteins involved in the pathogenesis of this condition.
\end{abstract}

Keywords: Adult hippocampal neurogenesis, Alzheimer's disease, granule neuron, GSK-3 $\beta$, morphology, neuroprotection, tau

\section{ALZHEIMER'S DISEASE: A FEW WORDS ABOUT TWO OF THE MAIN PLAYERS, GSK-3ß AND TAU}

Alzheimer's disease (AD) is the most common type of dementia in industrialized countries.

\footnotetext{
${ }^{1}$ These authors contributed equally to this work.

*Correspondence to: María Llorens-Martín, Centro de Biología Molecular "Severo Ochoa", Universidad Autónoma de Madrid (campus de Cantoblanco), c/Nicolás Cabrera 1, 28049, Madrid, Spain. Tel.: +34 911964592; E-mail: m.llorens@csic.es.
}

Although the etiology of the disease remains to be fully elucidated, age, genetic, lifestyle, and environmental factors appear to confer higher susceptibility [1]. AD is characterized by progressive neuronal cell death and atrophy of specific brain areas, including the entorhinal cortex (EC) and the hippocampus, and by a marked impairment of episodic memory $[2,3]$. The most relevant histopathological hallmarks of the disease are extracellular senile plaques made of amyloid- $\beta(\mathrm{A} \beta)$ protein, and neurofibrillary tangles, which are formed mainly by hyperphosphorylated tau 
protein. $A \beta$ and tau have been largely considered to be the cornerstones of AD pathogenesis [4]. Moreover, in vitro [5] and in vivo [6] studies showed that $\mathrm{A} \beta$ exerts its detrimental actions by activating a key kinase, namely glycogen synthase kinase $3 \beta$ (GSK$3 \beta)[5,7]$, thus revealing this kinase as an important player in the amyloid cascade. GSK-3 $\beta$ is the main kinase that phosphorylates tau $[7,8]$. Moreover, an increase in GSK-3 $\beta$ activity has been observed in the brains of AD patients [9]. These data have confirmed GSK-3 $\beta$ as a cornerstone of AD pathogenesis and support the notion that this kinase is a crucial molecular link between $\mathrm{A} \beta$ and tau [7, 8, 10-13]. Indeed, a transgenic animal model that overexpresses GSK$3 \beta$ in the hippocampus (namely GSK-3 $\beta$-oe mouse), generated in our laboratory, has been used to model the cellular and behavioral alterations that occur in $\mathrm{AD}$. In these mice, conditional overexpression (OE) of GSK-3 $\beta$ results in impaired spatial memory and increased tau phosphorylation in the hippocampus [14-16].

The present work is focused on the hippocampal region, given the relevance of this brain region in $\mathrm{AD}$ pathogenesis. It revises the available literature on the effects of GSK- $3 \beta$ and tau dysregulation on a specific neuronal population of this region, namely granule neurons. Special emphasis is placed on the therapeutic potential of diverse interventions aimed to increase hippocampal plasticity in AD.

\section{A FEW WORDS ABOUT ADULT HIPPOCAMPAL NEUROGENESIS (AHN)}

Adult neurogenesis is an infrequent phenomenon in the mammalian brain. Under physiological conditions, only a limited number of human brain regions, including the hippocampus [17], the sub-ventricular zone [18], and the striatum [19], experience this process throughout lifetime. AHN has attracted considerable interest mainly because of the involvement of the hippocampal region in learning and memory and the marked atrophy of this structure in patients with $\mathrm{AD}$ [20]. In the hippocampus, adult neurogenesis continuously gives rise to newborn granule neurons (NGNs) throughout life [17, 21-23]. These newly generated cells derive from a special population of radial glial-like precursor cells [24], which undergo several rounds of asymmetric division and generate transiently amplifying progenitors [25]. These cells actively divide in specialized neurogenic niches and go through several development stages before reaching full maturity [26, 27]. During maturation, NGNs extend their dendritic trees through the granule and the molecular layers (GL and ML) of the dentate gyrus (DG), where they receive afferent innervation from the EC [28] and inhibitory Parvalbumin ${ }^{+}$interneurons [29]. Moreover, they extend their axonal projections toward the CA3 [30] and the CA2 [31] hippocampal subfields. Importantly, numerous aspects of newborn neuron generation in the hippocampus, including proliferation, maturation, and survival rates, are altered in animal models of $\mathrm{AD}$ and in patients with this disease $[32,33]$.

\section{ORCHESTRATION OF AHN BY GSK-3ß AND TAU}

\section{Regulation of the rate of $A H N$}

In the DG, GSK-3 $\beta$ increases the proliferation of neuron precursors and prevents them from acquiring a neuronal fate [34]. Moreover, GSK-3 $\beta$ overactivation increases the apoptosis of mature granule neurons and blocks the differentiation of neuroblasts [35]. Interestingly, an increased number of Doublecortin $(\mathrm{DCX})^{+}$neuroblasts is observed in GSK-3ß-oe mice [35]. In this regard, the successive stages of AHN are featured by the expression of specific markers, and a stereotyped pattern of expression is thought to drive the maturation of these cells $[25,26,36]$. For instance, DCX expression is switched off at 3-4 weeks of cell age under physiological conditions. However, we found that its expression was aberrantly prolonged until the sixth week of cell age in GSK$3 \beta$-oe mice [35], thus rendering an increased number of neuroblasts whose maturational progression was blocked. As will be further discussed, this blockade has important consequences for NGN functionality in GSK-3 $\beta$-oe mice.

As previously mentioned, tau is one of the main downstream targets of GSK-3 $\beta$ and is considered a capital regulator of AHN [37, 38]. In this regard, both the expression and the post-transcriptional modifications of tau are tightly regulated during the maturation of NGNs [37-39]. For instance, the tau isoform featured by the presence of three-repeat microtubule-binding domains (namely, 3R-tau) is transiently expressed during the NGN neuroblast stage [38]. In rodents, individual NGNs show the highest expression of 3R-tau at 2 weeks of cell age [39], and the expression of this molecule is maintained until 4 weeks, a time point at which 3R-tau 

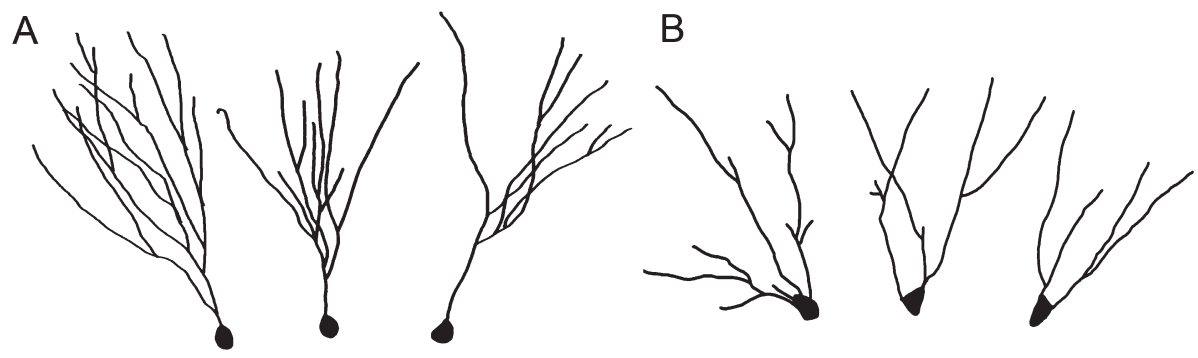

Fig. 1. Tracings of Golgi-stained granule neurons of control subjects (A) and patients with Alzheimer's disease (AD) (B). It should be noted how granule neurons of control subjects display a single primary apical dendrite emerging from the soma, thus resembling a "Y-shape", whereas granule neurons of $\mathrm{AD}$ patients show several primary apical dendrites that are poorly branched in the distal domains, thus acquiring a "V-shape".

is replaced by the four-repeat microtubule-binding domain form of the protein (4R-tau) [38]. By using an antigen retrieval protocol, we showed that 3R-tau is a transient marker of NGN axons [39]. Noteworthy, this isoform of tau confers the cytoskeleton with greater plasticity than the 4R-tau isoform and the expression of 3R-tau is coincident with the period of time in which NGNs exhibit highest plasticity [40]. Although the 3R-tau/4R-tau ratio in humans and rodents appears to differ [41], the absence of reliable human 3R-tau markers for immunohistochemistry determinations has hindered the detailed study of these regulatory mechanisms in the context of human AHN to date. However, it has been proposed that an imbalance in the aforementioned ratio underlies certain neurodegenerative diseases [42]. This notion deserves further exploration in the context of AD.

Despite the predominant role that tau is assumed to play in AHN regulation, tau knock-down does not cause alterations in the proliferation, differentiation, or survival rates of neural precursors in the DG in vivo [43]. In this regard, compensatory mechanisms exerted by other microtubule-associated proteins (MAPs), such as MAP-1A and MAP-1B $[44,45]$, occur in the absence of tau. In contrast to the apparent absence of alterations showed by tau knockout (tau-/-) mice regarding the basal rate of AHN, we and others have demonstrated that various animal models of tauopathies in which pathogenic forms of tau are overexpressed exhibit marked alterations in AHN $[37,46]$. In this regard, the overexpression of a pathogenic form of the protein is not only characterized by its lack of physiological functions but also by the gain of toxic functions. A recent study by our group also revealed that stereotaxic injection of a soluble form of tau has devastating effects on the structural plasticity of granule neurons and impairs pattern separation ability [47]. These data might be relevant for the field of neurodegenerative disorders, since they contribute to shedding light on novel pathological roles played by distinct tau species in vivo.

\section{The "V-shape" phenotype of newborn granule neurons in $A D$}

As previously mentioned, NGNs go through a multi-stage development process before they reach maturity [25]. Although fully mature newly and developmentally generated granule neurons were initially described to be undistinguishable [48], growing evidence indicates that they show both functional and anatomical differences [49]. Regarding the latter, these two types of granule neurons differ in their positioning with respect to the GL $[49,50]$. In this respect, NGNs are located in the inner third of the GL, whereas developmentally generated granule neurons are found in the two outer thirds of this layer [50]. Moreover, both types of cell show morphological particularities worthy of further discussion, the most remarkable difference being the number of primary apical dendrites. Under physiological conditions, most newly generated granule neurons show a single primary apical dendrite, which is extensively branched in the ML, thus resembling a "Y- shape" [49]. In contrast, developmentally generated granule neurons show several primary apical dendrites emerging from the soma [51]. In contrast to the scenario observed under physiological conditions, we showed that GSK-3 $\beta$ OE causes a dramatic change in the morphology of NGNs by triggering the presence of several primary apical dendrites, thereby conferring them a "V-shape" [16]. The relevance of this observation lies in the fact that the same morphology is observed in the granule neurons of AD patients [16]. Representative neuronal tracings corresponding to Golgi-stained granule neurons belonging to 
control subjects and AD patients are shown in Fig. 1. To the best of our knowledge, our work was the first to describe the occurrence of this phenomenon in AD patients; however, subsequent studies by other authors have revealed a similar "V-shape" phenotype, including the appearance of several primary apical dendrites in various pathological conditions [52-55]. Further efforts should address the molecular mechanisms involved in the appearance of this particular phenotype. In this regard, several molecules associated with the cytoskeleton may drive the development of dendritic branches and should be further explored in the context of neurodegenerative diseases [56].

Despite the observed marked effects of GSK-3 $\beta$ OE on the morphology of mouse NGNs, a critical question for the $\mathrm{AD}$ research field is whether these effects are a cell-autonomous consequence of GSK-3 $\beta$ OE or whether they represent a non-cellautonomous indirect effect derived from massive cell death or neuroinflammation. This question is particularly relevant in the context of $\mathrm{AHN}$, given that the promoter used to drive GSK-3 $\beta$ OE, namely CamKII, is active only in mature cells [16]. In order to address this point, we developed an innovative system to selectively drive GSK-3 $\beta$ OE in our target cells, namely NGNs $[57,58]$. This system takes advantage of the capacity of retroviruses to exclusively transduce proliferating cells and of the fact that proliferation is restricted mostly to NGNs in the DG [30]. This novel system is based on the stereotaxic injection of a retrovirus encoding the reverse Tetracycline activator (rtTA) element into the hippocampus of tetR-GSK-3 $\beta$ mice. These animals carry a bi-directional Tetracycline repressor (TetR) promoter followed by a GSK-3 $\beta$ cDNA in one direction and a cDNA encoding $\beta$-Galactosidase ( $\beta-\mathrm{Gal})$ fused to a nuclear localization signal in the other. By using this methodology, GSK-3 $\beta$ OE occurs only in those NGNs infected by the retrovirus and after the administration of Doxycycline. Thus, our novel methodology has three major advantages over traditional transgenic mouse systems. The first is the use of an rtTA element instead of the classical tTA element. This approach renders a tet-ON system in which GSK-3 $\beta$ OE is selectively triggered by the administration of Doxycycline- - a feature that allows precise temporal control of GSK-3 $\beta$ OE. The second advantage is that the system allows tight regulation of the age and type of cell populations that overexpress this protein by means of Doxycycline administration during the desired periods. Finally, the system allows the double monitoring of GSK-3 $\beta$ OE by means of two reporter proteins, namely EGFP (encoded by the retroviral genome) and $\beta$-Gal (encoded by the murine genome). As previously mentioned, this methodology allowed us to achieve rapid and selective GSK-3 $\beta$ OE in the NGNs infected by the retrovirus [57]. Using this strategy, we demonstrated the cell-autonomous character of the alterations triggered by GSK-3 $\beta$ OE in NGNs, which showed a "V-shape" phenotype only under tet-ON conditions.

This system shows great versatility and potential utility in the field of neurodegenerative diseases, since it has proved highly suitable for the study of the cell-autonomous effects of other pathogenic proteins involved in these conditions [58].

\section{Synaptic integration of newborn granule neurons}

Although the functional consequences of the morphological alterations previously described remain to be fully elucidated, we have proposed that a reduced dendritic mass in the ML decreases the afferent connectivity of NGNs by reducing the likelihood of distal dendrites receiving afferent contacts from the EC. This hypothesis is strongly supported by the clear detrimental effect of GSK-3 $\beta$ at the synapse [59]. In this regard, long-term depression downregulates long-term potentiation through GSK-3 $\beta$ activation $[60,61]$, a phenomenon which is followed by synapse elimination.

By using a PSD95:GFP-expressing retrovirus [62], we demonstrated that the NGNs of GSK-3 $\beta$-oe mice exhibit a marked reduction in the number and size of postsynaptic densities (PSDs), thus revealing impaired afferent connectivity $[16,63]$. Special mention should be given to the important consequences of selective impairment of the synaptic integration of NGNs on the whole trisynaptic circuit. In this regard, during the period in which NGNs are young and excitable [40], they are thought to play a key role in information processing along the hippocampal circuit $[64,65]$. In fact, it has been proposed that newly and developmentally generated granule neurons cooperate to create an accurate and complex representation of new memories. Developmentally generated granule neurons are believed to be involved mostly in pattern completion (an ability based on generalization) [66], whereas the lower activation threshold and higher excitability of NGNs favor their involvement in hippocampal pattern separation (a phenomenon consisting of the production of two differentiated outputs in response to very similar inputs) $[67,68]$. The continuous re-definition of 
this elegant hypothesis proposed by Sahay [68] and McHugh [67] is continuously revealing the existence of additional complex orchestration mechanisms. For instance, competition phenomena between newborn and developmentally generated neurons to establish synaptic contacts with afferent fibers from the EC may also drive the intricate communication between this structure and the DG [69, 70]. This notion has been further supported by an elegant study by Sahay et al., in which the authors observed that reducing the connectivity of mature granule neurons dramatically increases the survival, maturation, and number of NGNs and maturity of synaptic connections of these cells [71]. These observations may have important consequences in the context of pathological conditions involving an imbalance between the synaptic integration of newly and developmentally generated granule neurons. In this regard, we found a similar imbalance in a murine model of AD overexpressing GSK-3 $\beta$ (GSK-3 $\beta$-oe mice) in the hippocampus [51]. Granule neurons of these animals show a generalized reduction in the number of dendritic spines and synaptic contacts [51]. However, detailed morphometric analysis of these structures revealed that NGNs show a reduction in PSD volume (which in turn revealed a decrease in the synaptic strength of their afferent connections), whereas the dendritic spines of developmentally generated neurons show a marked enlargement (thereby suggesting a strengthening of the afferent connections of these cells). According to the competition hypothesis, these findings suggest the selectively impaired synaptic integration of NGNs in this animal model of AD. On the basis of the higher plasticity conferred by these cells to the hippocampal circuit, we have proposed that their reduced synaptic integration favors greater stability of old synaptic connections and a generalized lack of plasticity at the hippocampal level. Noteworthy, GSK-3 $\beta$-oe mice exhibit alterations in hippocampal-dependent behaviors requiring high behavioral flexibility, such as in pattern separation [55].

There is intense debate in the field as to whether competition phenomena established between newly and developmentally generated NGNs are a physiological mechanism aimed to compensate the reduced capacity of the oldest neurons to cope with insults, or whether the natural purpose of NGNs is to gradually replace the oldest cells in order to favor their withdrawal from the hippocampal circuit $[72,73]$. Nevertheless, the observation of these competition phenomena acquire particular relevance in the context of neurodegenerative diseases, given that impairments in pattern separation and in AHN have been found in $\mathrm{AD}$ patients and in animal models of this disease [32]. These observations and the extraordinary regenerative potential of AHN have placed this process in the spotlight of therapeutic strategies aimed to tackle neurodegenerative diseases.

By using the same retroviral approach previously mentioned, we demonstrated that GSK-3 $\beta$ OE increases tau phosphorylation in single NGNs in a cell-autonomous manner, thus revealing tau as a key mediator of the alterations in NGN functionality caused by GSK-3 $\beta$ OE. In this regard, despite the classical association of tau with the axonal compartment, growing evidence strongly supports the notion that this protein is present and involved in various functions of the somatodendritic compartment. In 2011, Ittner et al. [74] elegantly demonstrated the participation of tau in cortical synapses. In that study, the authors showed that tau depletion is neuroprotective against synapse destabilization caused by the presence of $A \beta$. More recently, these authors have demonstrated that tau phosphorylation finely tunes the synaptic roles played by tau [75]. It has been proposed that tau modulates the synaptic localization of Fyn kinase, which favors synapse stabilization [74]. On the other hand, tau phosphorylation by GSK$3 \beta$ increases tau aggregation and impedes several of its actions at the synapse. A detailed schematic diagram showing these regulatory mechanisms is shown in Fig. 2. In agreement with previous observations in other neuronal populations [74], our data reveal that the absence of tau impairs the synaptic integration of NGNs [43]. These alterations are particularly apparent in the most distal part of the dendritic tree, where the NGNs of tau-/- mice show the most drastic reduction in the number of PSDs, accompanied by a marked decrease in the volume of these structures [43]. Importantly, these data indicate that the synaptic integration of NGNs in tau-/- mice is impaired, as a result of a reduction in the connectivity of the outer parts of their dendritic trees with afferent fibers from the EC.

Nevertheless, the general consensus in the field is that the absence of tau confers a certain degree of neuroprotection in response to exposure to various toxic agents. In this regard, we demonstrated, for the first time, that the absence of tau conferred NGNs with extraordinary resistance to stress [43]. However, our results also showed that the absence of tau completely blocked the stimulatory actions exerted by environmental enrichment (EE) on NGNs. Of note, EE is one of the most potent positive regulators of $\mathrm{AHN}$ 
A

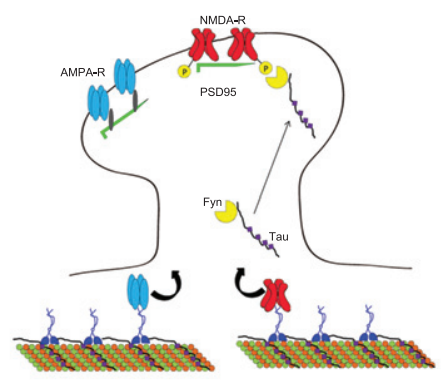

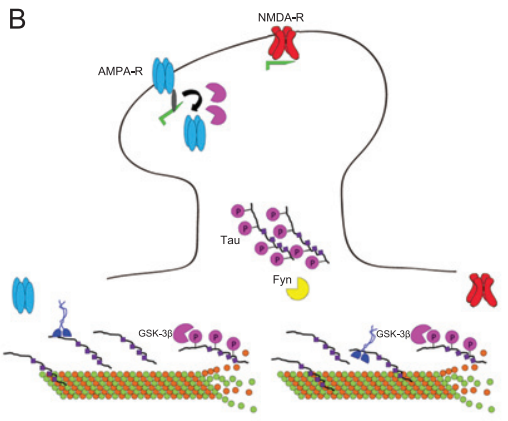

C

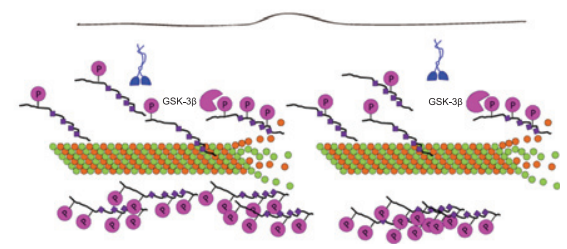

Fig. 2. Schematic model proposed to explain the mechanisms through which GSK-3 $\beta$ and tau regulate the synaptic integration of granule neurons. A) Under basal conditions, tau plays a central role at the synapses through its interaction with Fyn kinase. On the other hand, tau stabilizes microtubules, thus allowing the dendritic transport of synaptic receptors to the synapses, where they are stabilized through their interactions with the scaffold protein PSD95. GSK-3 $\beta$ exerts tau-dependent and -independent regulatory actions at the synapse. B) Under pathological conditions, GSK-3 $\beta$ overexpression increases tau phosphorylation. This phenomenon decreases tau affinity to bind microtubules, which are destabilized. On the one hand, this compromises dendritic transport. On the other hand, tau phosphorylation triggers its aggregation, which further impairs cell function. In addition, synapses are destabilized by tau-dependent and tau-independent mechanisms. C) The chronic maintenance of these pathological conditions leads to the disappearance of the synapse.

[76]. It increases the survival, maturation, and plasticity of NGNs in WT mice [77]. However, we did not observe these stimulatory effects in tau-/- NGNs [43]. Our results therefore indicate that tau depletion has a negative impact on neurodegenerative diseases by further decreasing the plasticity of especially sensitive neuronal populations. These data should be taken into account during the development of strategies aimed to ameliorate neurodegeneration caused by aberrant forms of tau. Special emphasis should be placed on identifying the physiological roles played by the various species of tau in specific neuronal populations, given that not all of these functions can be compensated by other MAPs.

\section{CONCLUDING REMARKS AND FUTURE DIRECTIONS}

Our current perception of AHN is continuously being modified by the addition of new brush-strokes that illustrate particular aspects of the orchestration mechanisms underlying AHN. Given the enormous complexity of the regulatory mechanisms driving the synaptic integration of NGNs into the preexisting trisynaptic circuits, future efforts should be focused on unraveling the fine boundary between the neuroprotective and detrimental actions exerted by GSK-3 $\beta$ and tau. In this regard, we have observed that the absence of tau blocks the stimulatory actions of EE on NGNs. On the other hand, we have found that GSK-3 $\beta$ OE prevents some of the stimula- tory actions of EE and physical exercise on NGN connectivity. Thus, both an increase in and blockade of the activity of certain proteins, such as GSK-3 $\beta$ or tau, may have equivalent detrimental effects on the structural plasticity of NGNs, a crucial cell population that shows marked alterations in animal models of AD models and patients with this condition. Hence, to achieve effectiveness, therapeutic strategies aimed to ameliorate the symptoms or to prevent the progression of AD should be particularly careful in the choice of pathological target and should ensure the maintenance of the essential physiological functions of these proteins.

\section{ACKNOWLEDGMENTS}

This work was supported by the Spanish Ministry of Economy and Competitiveness (SAF-201453040-P (Jesús Ávila) and RYC-2015-17189 (María Llorens-Martín)); the Centro de Investigación Biomé dica en Red sobre Enfermedades Neurodegenerativas (CIBERNED, Spain) (Jesús Ávila); the Alzheimer's Association (2015-NIRG-340709 (María LlorensMartín)); and the Association for Frontotemporal Degeneration (2016 Basic Science Pilot Grant Award (María Llorens-Martín)). These funding sources had no involvement in the design of the experiments, analysis of the data or manuscript preparation. Institutional grants from the Fundación Ramón Areces and Banco de Santander to the CBMSO are also acknowledged. 
The authors would like to thank Drs. FH. Gage, C. Lois, and F. Calegari for kindly providing the retroviral plasmids used in the experiments mentioned in the present work.

Authors' disclosures available online (https:// www.j-alz.com/manuscript-disclosures/17-9918).

\section{REFERENCES}

[1] Piaceri I, Nacmias B, Sorbi S (2013) Genetics of familial and sporadic Alzheimer's disease. Front Biosci (Elite Ed) 5, 167-177.

[2] Weiner MW, Veitch DP, Aisen PS, Beckett LA, Cairns NJ, Green RC, Harvey D, Jack CR Jr, Jagust W, Morris JC, Petersen RC, Saykin AJ, Shaw LM, Toga AW, Trojanowski JQ, Alzheimer's Disease Neuroimaging Initiative (2017) Recent publications from the Alzheimer's Disease Neuroimaging Initiative: Reviewing progress toward improved AD clinical trials. Alzheimers Dement 13, e1-e85.

[3] Raskin J, Cummings J, Hardy J, Schuh K, Dean RA (2015) Neurobiology of Alzheimer's disease: Integrated molecular, physiological, anatomical, biomarker, and cognitive dimensions. Curr Alzheimer Res 12, 712-722.

[4] Sanabria-Castro A, Alvarado-Echeverria I, Monge-Bonilla C (2017) Molecular pathogenesis of Alzheimer's disease: An update. Ann Neurosci 24, 46-54.

[5] Takashima A, Sato M, Mercken M, Tanaka S, Kondo S, Honda T, Sato K, Murayama M, Noguchi K, Nakazato Y, Takahashi H (1996) Localization of Alzheimer-associated presenilin 1 in transfected COS-7 cells. Biochem Biophys Res Commun 227, 423-426.

[6] Terwel D, Muyllaert D, Dewachter I, Borghgraef P, Croes S, Devijver H, Van Leuven F (2008) Amyloid activates GSK3 beta to aggravate neuronal tauopathy in bigenic mice. Am J Pathol 172, 786-798.

[7] Takashima A, Noguchi K, Michel G, Mercken M, Hoshi M, Ishiguro K, Imahori K (1996) Exposure of rat hippocampal neurons to amyloid beta peptide (25-35) induces the inactivation of phosphatidyl inositol-3 kinase and the activation of tau protein kinase I/glycogen synthase kinase-3 beta. Neurosci Lett 203, 33-36.

[8] Llorens-Martin M, Jurado J, Hernandez F, Avila J (2014) GSK-3beta, a pivotal kinase in Alzheimer disease. Front Mol Neurosci 7, 46.

[9] Leroy K, Yilmaz Z, Brion JP (2007) Increased level of active GSK-3beta in Alzheimer's disease and accumulation in argyrophilic grains and in neurones at different stages of neurofibrillary degeneration. Neuropathol Appl Neurobiol 33, 43-55.

[10] Avila J, Hernandez F (2007) GSK-3 inhibitors for Alzheimer's disease. Expert Rev Neurother 7, 1527-1533.

[11] Engel T, Goni-Oliver P, Lucas JJ, Avila J, Hernandez F (2006) Chronic lithium administration to FTDP-17 tau and GSK-3beta overexpressing mice prevents tau hyperphosphorylation and neurofibrillary tangle formation, but pre-formed neurofibrillary tangles do not revert. $\mathrm{J} \mathrm{Neu}$ rochem $99,1445-1455$.

[12] Hernandez F, de Barreda EG, Fuster-Matanzo A, GoniOliver P, Lucas JJ, Avila J (2009) The role of GSK3 in Alzheimer disease. Brain Res Bull 80, 248-250.

[13] Hernandez F, Gomez de Barreda E, Fuster-Matanzo A, Lucas JJ, Avila J (2010) GSK3: A possible link between beta amyloid peptide and tau protein. Exp Neurol 223, 322-325.

[14] Hernandez F, Borrell J, Guaza C, Avila J, Lucas JJ (2002) Spatial learning deficit in transgenic mice that conditionally over-express GSK-3beta in the brain but do not form tau filaments. J Neurochem 83, 1529-1533.

[15] Lucas JJ, Hernandez F, Gomez-Ramos P, Moran MA, Hen R, Avila J (2001) Decreased nuclear beta-catenin, tau hyperphosphorylation and neurodegeneration in GSK-3beta conditional transgenic mice. EMBO J 20, 27-39.

[16] Llorens-Martin M, Fuster-Matanzo A, Teixeira CM, JuradoArjona J, Ulloa F, Defelipe J, Rabano A, Hernandez F, Soriano E, Avila J (2013) GSK-3beta overexpression causes reversible alterations on postsynaptic densities and dendritic morphology of hippocampal granule neurons in vivo. Mol Psychiatry 18, 451-460.

[17] Eriksson PS, Perfilieva E, Bjork-Eriksson T, Alborn AM, Nordborg C, Peterson DA, Gage FH (1998) Neurogenesis in the adult human hippocampus. Nat Med 4, 1313-1317.

[18] Doetsch F, Caille I, Lim DA, Garcia-Verdugo JM, AlvarezBuylla A (1999) Subventricular zone astrocytes are neural stem cells in the adult mammalian brain. Cell 97, 703-716.

[19] Bergmann O, Spalding KL, Frisen J (2015) Adult neurogenesis in humans. Cold Spring Harb Perspect Biol 7, a018994.

[20] Kantarci K, Jack CR Jr (2003) Neuroimaging in Alzheimer disease: An evidence-based review. Neuroimaging Clin N Am 13, 197-209.

[21] Altman J, Das GD (1965) Autoradiographic and histological evidence of postnatal hippocampal neurogenesis in rats. J Comp Neurol 124, 319-335.

[22] Cameron HA, Gould E (1994) Adult neurogenesis is regulated by adrenal steroids in the dentate gyrus. Neuroscience 61, 203-209.

[23] Kuhn HG, Dickinson-Anson H, Gage FH (1996) Neurogenesis in the dentate gyrus of the adult rat: Age-related decrease of neuronal progenitor proliferation. J Neurosci 16, 2027-2033.

[24] Seri B, Garcia-Verdugo JM, McEwen BS, Alvarez-Buylla A (2001) Astrocytes give rise to new neurons in the adult mammalian hippocampus. J Neurosci 21, 7153-7160.

[25] Kempermann G, Jessberger S, Steiner B, Kronenberg G (2004) Milestones of neuronal development in the adult hippocampus. Trends Neurosci 27, 447-452.

[26] Kronenberg G, Reuter K, Steiner B, Brandt MD, Jessberger S, Yamaguchi M, Kempermann G (2003) Subpopulations of proliferating cells of the adult hippocampus respond differently to physiologic neurogenic stimuli. J Comp Neurol 467, 455-463.

[27] Brandt MD, Jessberger S, Steiner B, Kronenberg G, Reuter K, Bick-Sander A, von der Behrens W, Kempermann G (2003) Transient calretinin expression defines early postmitotic step of neuronal differentiation in adult hippocampal neurogenesis of mice. Mol Cell Neurosci 24, 603-613.

[28] Hyman BT, Kromer LJ, Van Hoesen GW (1987) Reinnervation of the hippocampal perforant pathway zone in Alzheimer's disease. Ann Neurol 21, 259-267.

[29] Alvarez DD, Giacomini D, Yang SM, Trinchero MF, Temprana SG, Buttner KA, Beltramone N, Schinder AF (2016) A disynaptic feedback network activated by experience promotes the integration of new granule cells. Science 354, 459-465.

[30] Zhao C, Teng EM, Summers RG Jr, Ming GL, Gage FH (2006) Distinct morphological stages of dentate granule neuron maturation in the adult mouse hippocampus. $\mathrm{J} \mathrm{Neu}$ rosci 26, 3-11. 
[31] Llorens-Martin M, Jurado-Arjona J, Avila J, Hernandez F (2015) Novel connection between newborn granule neurons and the hippocampal CA2 field. Exp Neurol 263, 285-292.

[32] Hollands C, Bartolotti N, Lazarov O (2016) Alzheimer's disease and hippocampal adult neurogenesis; exploring shared mechanisms. Front Neurosci 10, 178.

[33] Gomez-Nicola D, Suzzi S, Vargas-Caballero M, Fransen NL, Al-Malki H, Cebrian-Silla A, Garcia-Verdugo JM, Riecken K, Fehse B, Perry VH (2014) Temporal dynamics of hippocampal neurogenesis in chronic neurodegeneration. Brain 137, 2312-2328.

[34] Eom TY, Jope RS (2009) Blocked inhibitory serinephosphorylation of glycogen synthase kinase-3alpha/beta impairs in vivo neural precursor cell proliferation. Biol Psychiatry 66, 494-502.

[35] Fuster-Matanzo A, Llorens-Martin M, Sirerol-Piquer MS, Garcia-Verdugo JM, Avila J, Hernandez F (2013) Dual effects of increased glycogen synthase kinase-3beta activity on adult neurogenesis. Hum Mol Genet 22, 1300-1315.

[36] Esposito MS, Piatti VC, Laplagne DA, Morgenstern NA, Ferrari CC, Pitossi FJ, Schinder AF (2005) Neuronal differentiation in the adult hippocampus recapitulates embryonic development. J Neurosci 25, 10074-10086.

[37] Fuster-Matanzo A, Llorens-Martin M, Jurado-Arjona J, Avila J, Hernandez F (2012) Tau protein and adult hippocampal neurogenesis. Front Neurosci 6, 104.

[38] Bullmann T, de Silva R, Holzer M, Mori H, Arendt T (2007) Expression of embryonic tau protein isoforms persist during adult neurogenesis in the hippocampus. Hippocampus 17, 98-102.

[39] Llorens-Martin M, Teixeira CM, Fuster-Matanzo A, JuradoArjona J, Borrell V, Soriano E, Avila J, Hernandez F (2012) Tau isoform with three microtubule binding domains is a marker of new axons generated from the subgranular zone in the hippocampal dentate gyrus: Implications for Alzheimer's disease. J Alzheimers Dis 29, 921-930.

[40] Bischofberger J (2007) Young and excitable: New neurons in memory networks. Nat Neurosci 10, 273-275.

[41] Chen S, Townsend K, Goldberg TE, Davies P, ConejeroGoldberg C (2010) MAPT isoforms: Differential transcriptional profiles related to $3 \mathrm{R}$ and $4 \mathrm{R}$ splice variants. J Alzheimers Dis 22, 1313-1329.

[42] Fernandez-Nogales M, Cabrera JR, Santos-Galindo M, Hoozemans JJ, Ferrer I, Rozemuller AJ, Hernandez F, Avila J, Lucas JJ (2014) Huntington's disease is a fourrepeat tauopathy with tau nuclear rods. Nat Med 20, 881-885

[43] Pallas-Bazarra N, Jurado-Arjona J, Navarrete M, Esteban JA, Hernandez F, Avila J, Llorens-Martin M (2016) Novel function of tau in regulating the effects of external stimuli on adult hippocampal neurogenesis. EMBO J 35, 1417-1436.

[44] Takemura R, Okabe S, Umeyama T, Kanai Y, Cowan NJ, Hirokawa N (1992) Increased microtubule stability and alpha tubulin acetylation in cells transfected with microtubule-associated proteins MAP1B, MAP2 or tau. J Cell Sci 103(Pt 4), 953-964.

[45] Takei Y, Kondo S, Harada A, Inomata S, Noda T, Hirokawa $N$ (1997) Delayed development of nervous system in mice homozygous for disrupted microtubule-associated protein 1B (MAP1B) gene. J Cell Biol 137, 1615-1626.

[46] Llorens-Martin M, Hernandez F, Avila J (2011) Expression of frontotemporal dementia with parkinsonism associated to chromosome 17 tau induces specific degeneration of the ventral dentate gyrus and depressive-like behavior in mice. Neuroscience 196, 215-227.

[47] Bolós M, Pallas-Bazarra N, Terreros-Roncal J, Perea JR, Jurado-Arjona J, Ávila J, Llorens-Martín M (2017) Soluble tau has devastating effects on the structural plasticity of hippocampal granule neurons. Transl Psychiatry 7, 1267.

[48] Laplagne DA, Esposito MS, Piatti VC, Morgenstern NA, Zhao C, van Praag H, Gage FH, Schinder AF (2006) Functional convergence of neurons generated in the developing and adult hippocampus. PLoS Biol 4, e409.

[49] Llorens-Martin M, Rabano A, Avila J (2015) The everchanging morphology of hippocampal granule neurons in physiology and pathology. Front Neurosci 9, 526.

[50] Kempermann G, Gast D, Kronenberg G, Yamaguchi M, Gage FH (2003) Early determination and long-term persistence of adult-generated new neurons in the hippocampus of mice. Development 130, 391-399.

[51] Pallas-Bazarra N, Kastanauskaite A, Avila J, DeFelipe J, Llorens-Martin M (2017) GSK-3beta overexpression alters the dendritic spines of developmentally generated granule neurons in the mouse hippocampal dentate gyrus. Front Neuroanat 11, 18.

[52] Murphy BL, Danzer SC (2011) Somatic translocation: A novel mechanism of granule cell dendritic dysmorphogenesis and dispersion. J Neurosci 31, 2959-2964.

[53] Jessberger S, Aigner S, Clemenson GD Jr, Toni N, Lie DC, Karalay O, Overall R, Kempermann G, Gage FH (2008) Cdk5 regulates accurate maturation of newborn granule cells in the adult hippocampus. PLoS Biol 6, e272.

[54] Llorens-Martin M, Jurado-Arjona J, Bolos M, PallasBazarra N, Avila J (2016) Forced swimming sabotages the morphological and synaptic maturation of newborn granule neurons and triggers a unique pro-inflammatory milieu in the hippocampus. Brain Behav Immun 53, 242-254.

[55] Llorens-Martin M, Jurado-Arjona J, Fuster-Matanzo A, Hernandez F, Rabano A, Avila J (2014) Peripherally triggered and GSK-3beta-driven brain inflammation differentially skew adult hippocampal neurogenesis, behavioral pattern separation and microglial activation in response to ibuprofen. Transl Psychiatry 4, e463.

[56] Baas PW, Karabay A, Qiang L (2005) Microtubules cut and run. Trends Cell Biol 15, 518-524.

[57] Llorens-Martin M, Teixeira CM, Jurado-Arjona J, Rakwal R, Shibato J, Soya H, Avila J (2016) Retroviral induction of GSK-3beta expression blocks the stimulatory action of physical exercise on the maturation of newborn neurons. Cell Mol Life Sci 73, 3569-3582.

[58] Teixeira CM, Avila J, Llorens-Martin M (2017) Versatile use of rtTA-expressing retroviruses in the study of neurodegeneration. Oncotarget 8, 10771-10772.

[59] Arendt T (2003) Synaptic plasticity and cell cycle activation in neurons are alternative effector pathways: The 'Dr. Jekyll and Mr. Hyde concept' of Alzheimer's disease or the yin and yang of neuroplasticity. Prog Neurobiol 71, 83-248.

[60] Peineau S, Taghibiglou C, Bradley C, Wong TP, Liu L, Lu J, Lo E, Wu D, Saule E, Bouschet T, Matthews P, Isaac JT, Bortolotto ZA, Wang YT, Collingridge GL (2007) LTP inhibits LTD in the hippocampus via regulation of GSK3beta. Neuron 53, 703-717.

[61] Hooper C, Markevich V, Plattner F, Killick R, Schofield E, Engel T, Hernandez F, Anderton B, Rosenblum K, Bliss T, Cooke SF, Avila J, Lucas JJ, Giese KP, Stephenson J, Lovestone S (2007) Glycogen synthase kinase-3 inhibition is integral to long-term potentiation. Eur J Neurosci 25, 81-86. 
[62] Kelsch W, Lin CW, Lois C (2008) Sequential development of synapses in dendritic domains during adult neurogenesis. Proc Natl Acad Sci U S A 105, 16803-16808.

[63] Llorens-Martin M, Fuster-Matanzo A, Teixeira CM, JuradoArjona J, Ulloa F, Defelipe J, Rabano A, Hernandez F, Soriano E, Avila J (2013) Alzheimer disease-like cellular phenotype of newborn granule neurons can be reversed in GSK-3beta-overexpressing mice. Mol Psychiatry 18, 395.

[64] Wiskott L, Rasch MJ, Kempermann G (2006) A functional hypothesis for adult hippocampal neurogenesis: Avoidance of catastrophic interference in the dentate gyrus. Hippocampus 16, 329-343.

[65] Marin-Burgin A, Mongiat LA, Pardi MB, Schinder AF (2012) Unique processing during a period of high excitation/inhibition balance in adult-born neurons. Science $\mathbf{3 3 5}$, 1238-1242.

[66] Nakashiba T, Cushman JD, Pelkey KA, Renaudineau S, Buhl DL, McHugh TJ, Rodriguez Barrera V, Chittajallu R, Iwamoto KS, McBain CJ, Fanselow MS, Tonegawa S (2012) Young dentate granule cells mediate pattern separation, whereas old granule cells facilitate pattern completion. Cell 149, 188-201.

[67] McHugh TJ, Jones MW, Quinn JJ, Balthasar N, Coppari R, Elmquist JK, Lowell BB, Fanselow MS, Wilson MA, Tonegawa S (2007) Dentate gyrus NMDA receptors mediate rapid pattern separation in the hippocampal network. Science 317, 94-99.

[68] Sahay A, Scobie KN, Hill AS, O'Carroll CM, Kheirbek MA, Burghardt NS, Fenton AA, Dranovsky A, Hen R (2011) Increasing adult hippocampal neurogenesis is sufficient to improve pattern separation. Nature 472, 466-470.

[69] Toni N, Sultan S (2011) Synapse formation on adult-born hippocampal neurons. Eur J Neurosci 33, 1062-1068.

[70] Krzisch M, Temprana SG, Mongiat LA, Armida J, Schmutz V, Virtanen MA, Kocher-Braissant J, Kraftsik R, Vutskits L, Conzelmann KK, Bergami M, Gage FH, Schinder
AF, Toni N (2015) Pre-existing astrocytes form functional perisynaptic processes on neurons generated in the adult hippocampus. Brain Struct Funct 220, 2027-2042.

[71] McAvoy KM, Scobie KN, Berger S, Russo C, Guo N, Decharatanachart P, Vega-Ramirez H, Miake-Lye S, Whalen M, Nelson M, Bergami M, Bartsch D, Hen R, Berninger B, Sahay A (2016) Modulating neuronal competition dynamics in the dentate gyrus to rejuvenate aging memory circuits. Neuron 91, 1356-1373.

[72] Lopez CM, Pelkey KA, Chittajallu R, Nakashiba T, Toth K, Tonegawa S, McBain CJ (2012) Competition from newborn granule cells does not drive axonal retraction of silenced old granule cells in the adult hippocampus. Front Neural Circuits 6, 85.

[73] Tronel S, Charrier V, Sage C, Maitre M, Leste-Lasserre T, Abrous DN (2015) Adult-born dentate neurons are recruited in both spatial memory encoding and retrieval. Hippocampus 25, 1472-1479.

[74] Ittner LM, Gotz J (2011) Amyloid-beta and tau-a toxic pas de deux in Alzheimer's disease. Nat Rev Neurosci 12, 65-72.

[75] Ittner A, Chua SW, Bertz J, Volkerling A, van der Hoven J, Gladbach A, Przybyla M, Bi M, van Hummel A, Stevens CH, Ippati S, Suh LS, Macmillan A, Sutherland G, Kril JJ, Silva AP, Mackay J, Poljak A, Delerue F, Ke YD, Ittner LM (2016) Site-specific phosphorylation of tau inhibits amyloid-beta toxicity in Alzheimer's mice. Science 354, 904-908.

[76] Kempermann G, Kuhn HG, Gage FH (1997) More hippocampal neurons in adult mice living in an enriched environment. Nature 386, 493-495.

[77] van Praag H, Kempermann G, Gage FH (2000) Neural consequences of environmental enrichment. Nat Rev Neurosci 1, 191-198. 